\title{
Correction to: Three dimensional characteristics of biopores and non-biopores in the subsoil respond differently to land use and fertilization
}

\author{
Zhongbin Zhang • Kailou Liu • Hu Zhou • Henry Lin • \\ Daming Li • Xinhua Peng
}

Published online: 22 June 2018

C) Springer International Publishing AG, part of Springer Nature 2018

Correction to: Plant Soil (2018) 428, 453-467

https://doi.org/10.1007/s11104-018-3689-3

The published online article unfortunately has an error in equation (2). The corrected form for the equation (2) is:

compactness $=\frac{A^{1.5}}{V}$

We are sorry for this inconvenience.

The online version of the original article can be found at https://doi.org/10.1007/s11104-018-3689-3

Z. Zhang $\cdot$ H. Zhou $\cdot$ X. Peng $(\bowtie)$

State Key Laboratory of Soil and Sustainable Agriculture, Institute of Soil Science, CAS, Nanjing 210008, China

e-mail: xhpeng@issas.ac.cn

K. Liu • D. Li

National Engineering and Technology Research Center for Red

Soil Improvement, Jiangxi Institute of Red Soil,

Nanchang 331717, China

H. Lin

Department of Ecosystem Sciences and Management,

Pennsylvania State University, University Park, PA 16802, USA 